\title{
Immunological events in acute measles influencing outcome
}

\author{
H. M. COOVADIA, A. WESLEY, AND P. BRAIN
}

From the Department of Paediatrics and Child Health, and Natal Institute of Immunology, University of Natal, Durban

SUMMARY $77 \%$ of 30 children with measles who had severe lymphopenia $\left(<2000 / \mathrm{mm}^{3}\right.$; $<2 \cdot 0 \times 10^{9} / 1$ ) within 2 days of appearance of rash (group A) subsequently died or progressed to chronic chest disease. This was significantly worse than the outcome in 30 children with measles who had lymphocyte counts $>2000 / \mathrm{mm}^{3}\left(>2 \cdot 0 \times 10^{9} / \mathrm{l}\right.$ ) (group B) of whom $67 \%$ recovered. In group $\mathrm{A}$ children the persistence of severe lymphopenia (caused by a reduction in $\mathrm{T}$ - and B-cells) for at least 15 days after onset of rash, remained a good predictive index of morbidity and mortality. Reversal of immunoparesis in group A was slower and incomplete 42 days from appearance of the rash in those who subsequently died or developed chronic chest disease compared with those who recovered. All patients who died failed to produce adequate measles antibodies. The therapeutic implications and immunopathological significance of these findings for chronic complications after acute measles are discussed.

Lymphocytes which are necessary for mediating specific immune responses (Gowans, 1968-69) are easily and frequently measured in the peripheral blood and infrequently reduced in common illnesses (Zacharski and Linman, 1971). There appears to be an important link between lymphocyte numbers and the immediate and late complications of certain neoplastic and infectious diseases (Papatestas and Kark, 1974; Coovadia et al., 1977; Jackson et al., 1977). Profound lymphopenia $\left(<2000 / \mathrm{mm}^{3} ;<2 \cdot 0\right.$ $\left.\times 10^{9} / 1\right)$ during the exanthem in measles, generally distinguishes children who will die or develop chronic chest disease from those who will recover (Coovadia et al., 1977).

There is extensive immunosuppression during acute measles (Coovadia et al., 1978) and elements of this persist for periods varying from 6 (Starr and Berkovich, 1964) to 52 weeks (Kipps et al., 1966). In children with the late pulmonary sequelae (Coovadia et al., 1978) and with subacute sclerosing panencephalitis (SSPE) (Valdimarsson et al., 1974), there is a relative sparing of most measured indices of immunity with some subtle immunological abnormalities. The sequence of immunological events occurring between paresis in acute severe disease and rehabilitation during chronicity is not understood. Elucidation of these changes

Received 23 January 1978 would assist in understanding the pathogenesis of chronic disease and may help in its prevention.

We have attempted to clarify these points and consolidate our earlier findings (Coovadia et al., 1977) by studying 30 children with measles who had an initial severe lymphopenia $\left(<2000 / \mathrm{mm}^{3}\right)$ sequentially, from acute rash to recovery, chronic chest disease, or death. The outcome in this group has been compared with that in 30 children with a moderate initial lymphopenia $\left(>2000 / \mathrm{mm}^{3}\right)$ during measles.

\section{Patients}

The nutritional state of all patients investigated was satisfactory. None had any of the clinical features of protein-calorie malnutrition and all were between the 10th and 75th Harvard centiles for weight with serum albumin $>3.0 \mathrm{~g} / 100 \mathrm{ml}(30 \mathrm{~g} / \mathrm{l})$ (Table 1$)$.

Group A. 30 African children with absolute lymphocyte counts $<2000 / \mathrm{mm}^{3}$ at 48 hours after the onset of the rash were studied sequentially. Blood for immunological studies (see methods) was taken within the first 15 days and on the 21st and 42nd day after the appearance of the rash. Chest $x$-rays were done on admission and on 42nd day. Their mean age was 19 months (range 6-72) and 14 were girls. 
Table 1 Nutritional parameters in groups $A$ and $B$

\begin{tabular}{lll}
\hline & \multicolumn{1}{l}{ Group } \\
\cline { 2 - 3 } & $A$ & $B$ \\
\hline $\begin{array}{l}\text { Clinical features of protein-calorie } \\
\text { malnutrition }\end{array}$ & Absent & Absent \\
$\begin{array}{l}\text { Harvard centiles of weight-for-age } \\
10-50\end{array}$ & $16^{*}$ & 18 \\
$\begin{array}{c}50-75 \\
\text { Serum albumin (g/1) }\end{array}$ & $38 \pm 0.62 \dagger$ & 12 \\
\hline
\end{tabular}

*Number of patients.

$\dagger$ Mean \pm standard error.

Differences between groups A and B for weight and serum albumin are not significant.

Group B. 30 African children with absolute lymphocyte counts $>2000 / \mathrm{mm}^{3}$ within 48 hours of the appearance of the rash, had their clinical course noted and chest $x$-rays done on admission and on day 42. Their mean age was 13 months (range 5-60) and 17 were girls.

Normal controls. 30 healthy children, race and age matched with those in group $\mathbf{A}$, had immunological tests (see methods), except for measles antibodies.

Chronie chest disease. Observations in this unit suggest that children who have radiological evidence of pneumonia 6 weeks after appearance of measles rash, usually run a fluctuating course for months or years with persistent lung changes. For purposes of this study, chest $x$-rays taken on the 6th week were examined independently by a consultant radiologist and one of us (A.W.) without foreknowledge of the patient's clinical condition or group status.

Bronchopulmonary changes were graded out of a total of 11 in the following manner: points to a maximum of 4 were awarded for areas of patchy consolidation, and one point each for atelectasis, involvement of peripheral lung fields-either by consolidation or emphysema-or for effusion. Increased vascular markings, increased interstitial pattern, and hilar shadow were each given a point. As these last three features are common in viral infection and not of great pathophysiological significance, an abnormal score was 4 or more. Children with a score of 4 or more on the chest $x$-ray after 6 weeks were classified as having chronic chest disease.

\section{Methods}

Lymphocytes were obtained from defribinated peripheral blood passed through 'Ficoll Hypaque' columns. Subpopulations of lymphocytes were counted in a single preparation by means of sheep rosette formation and by an immunofluorescence method for detecting immunoglobulins described elsewhere (Brain et al., 1976). Peripheral lymphocytes were classified as rosetting cells (T), fluorescing cells (B), cells with no markers (null), and those with both markers (FT).

Complement component C3 was estimated in plasma by radial immunodiffusion. Measles complement fixing antibodies were measured in sera by a standard microtitre method using specific antigen. Statistical analysis of results was carried out by either the Student's $t$ or $\chi^{2}$ test.

\section{Results}

Initial lymphocyte counts and outcome (groups A and B). The mean initial absolute lymphocyte counts

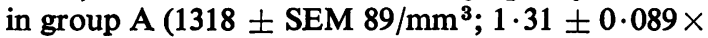
$\left.10^{9} / \mathrm{l}\right)$ and group $B\left(4232 \pm 314 / \mathrm{mm}^{3} ; 4 \cdot 23 \pm 0 \cdot 31\right.$ $\left.\times 10^{9} / 1\right)$ were lower $(\mathrm{P}<0.0005$ for both $)$ than that in healthy controls $\left(6833 \pm 553 / \mathrm{mm}^{3} ; 6.83 \pm 0.55\right.$ $\left.\times 10^{9} / 1\right)$. In group A there was clinical recovery in 7 children, chronic chest disease in 14, and death in 9. However, in group B, 20 patients recovered, 10 progressed to chronic chest disease, and none died. The differences between these two groups of patients for failure to recover (i.e. chronicity or death) and for progression to chronic chest disease alone, are significant $(\mathrm{P}<0.01, \mathrm{P}<0.05$ respectively). In neither group was there a significant difference in mean absolute lymphocyte counts in those in whom the course was unfavourable compared with those in whom the outcome was good. The mean age in group A children who recovered was 20 months (range 9-36), in those who developed chronicity it was 22 months (range 6-72), and in those who died it was 13 months (range 6-24). These differences are not significant $(P>0.05)$. The 9 deaths occurred between 4 and 65 days after appearance of the rash and after a clinical course characterised by severe progressive pneumonia.

Sequential lymphocyte counts and lymphocyte subpopulations (group A). (Table 2 and Figs 1-3). There was a rapid rise in absolute lymphocytes within 15 days of appearance of the rash. However, during this period, of 14 patients whose lymphocyte counts did not rise above $2000 / \mathrm{mm}^{3}$ (i.e. $30 \%$ of normal control value), 12 failed to recover ( 6 died, 6 chronic chest disease). Similarly, of 10 patients whose T-cells persisted below $1268 / \mathrm{mm}^{3}\left(1.26 \times 10^{9} / 1\right)$ (i.e. $30 \%$ of controls), 9 did not recover (4 died, 5 chronic chest disease), and of 14 children whose B-cells remained less than $556 / \mathrm{mm}^{3} ;\left(0.55 \times 10^{9} / 1\right)$ (i.e. $30 \%$ of controls), 12 did badly (6 died, 6 chronic chest disease). During this period null cells were highest 
Table 2 Lymphocyte subpopulations in group A patients and controls

\begin{tabular}{|c|c|c|c|c|c|c|c|}
\hline \multirow[t]{2}{*}{ Case no. } & \multirow{2}{*}{$\begin{array}{l}\text { Day after } \\
\text { onset of rash }\end{array}$} & \multirow{2}{*}{$\begin{array}{l}\text { Absolute } \\
\text { lymphocytes }\end{array}$} & \multicolumn{4}{|c|}{ Lymphocyte subpopulations } & \multirow{2}{*}{$\begin{array}{l}C X R \text { grades } \\
\text { on } 42 \text { nd day }\end{array}$} \\
\hline & & & $T$ & $\boldsymbol{B}$ & Null & $F T$ & \\
\hline \multicolumn{8}{|c|}{ Patients who recovered } \\
\hline 1 & 2 & 1650 & - & - & - & - & 3 \\
\hline 2 & 3 & 3741 & 2132 & 1459 & 150 & 37 & 3 \\
\hline 3 & 5 & 4680 & 3931 & 468 & 281 & 187 & 2 \\
\hline 4 & 5 & 4290 & 3218 & 815 & 257 & o & 1 \\
\hline 6 & 7 & 1200 & 924 & 228 & 48 & $\mathbf{0}$ & 2 \\
\hline 7 & 8 & 4840 & 3775 & 1016 & 48 & 48 & 3 \\
\hline All & 21 & $\begin{array}{l}6684 \pm 1833^{*} \\
>0.05 t\end{array}$ & $\begin{array}{l}5022 \pm 1159 \\
>0.05\end{array}$ & $\begin{array}{l}1513 \pm 674 \\
>0.05\end{array}$ & $\begin{array}{l}150 \pm 66 \\
<0.001\end{array}$ & $\begin{array}{l}108 \pm 45 \\
>0.05\end{array}$ & \\
\hline All & 42 & $\begin{array}{l}7248 \pm 1258 \\
>0.05\end{array}$ & $\begin{array}{l}5603 \pm 901 \\
>0.05\end{array}$ & $\begin{array}{l}1459 \pm 342 \\
>0.05\end{array}$ & $\begin{array}{l}187 \pm 92 \\
<0.001\end{array}$ & $\begin{array}{l}129 \pm 83 \\
>0.05\end{array}$ & \\
\hline \multicolumn{8}{|c|}{ Patients who developed chronic chest disease or died } \\
\hline 8 & 2 & 2337 & 1355 & 935 & 47 & 47 & 9 \\
\hline 11 & 2 & 1530 & - & - & - & - & Died \\
\hline 12 & 3 & 1836 & 1246 & 294 & 294 & $\mathbf{0}$ & Died \\
\hline 13 & 3 & 1032 & 753 & 237 & 41 & 21 & Died \\
\hline 14 & 3 & 4464 & 3660 & 625 & 179 & 0 & 4 \\
\hline 15 & 4 & 936 & - & - & - & - & Died \\
\hline 16 & 5 & 1870 & 1103 & 524 & 243 & 0 & Died \\
\hline 17 & 5 & 530 & 201 & 329 & 0 & 0 & 4 \\
\hline 18 & 6 & 5002 & 3902 & 950 & 150 & 200 & 4 \\
\hline 19 & 7 & 2790 & 2009 & 502 & 279 & 112 & Died \\
\hline 20 & 7 & 1287 & 978 & 309 & 0 & 103 & 4 \\
\hline 21 & 7 & 910 & 783 & 109 & 18 & 0 & 6 \\
\hline 22 & 8 & 10564 & 6972 & 1268 & 2324 & 0 & 7 \\
\hline 23 & 8 & 1836 & 1175 & 294 & 367 & 73 & 8 \\
\hline 24 & 9 & 720 & 583 & 108 & 29 & 0 & 6 \\
\hline 25 & 9 & 6000 & 4680 & 1320 & 0 & 0 & 9 \\
\hline 26 & 10 & 9300 & 6789 & 1953 & 558 & 186 & 5 \\
\hline 27 & 11 & 3472 & 2535 & 451 & 486 & 0 & 7 \\
\hline 28 & 12 & 4300 & 3526 & 473 & 301 & 0 & Died \\
\hline All§ & 42 & $5075 \pm 633$ & $3881 \pm 447$ & $1078 \pm 195$ & $126 \pm 36$ & $194 \pm 43$ & \\
\hline \multicolumn{8}{|c|}{ Healthy controls } \\
\hline Meatiny & & $6833 \pm 553^{*}$ & $4228 \pm 365$ & $1854 \pm 169$ & $756 \pm 96$ & $121 \pm 38$ & \\
\hline
\end{tabular}

*Mean \pm standard error.

†P value of difference between patients and controls.

$\ddagger$ Results of 5 patients; §Results of 10 patients; //results of 15 patients.

in 6 patients who did not recover ( 2 died, 4 chronic chest disease) and, of 14 children who had an absence of FT cells, 12 did not recover (4 died, 8 chronic chest disease).

The distinguishing pattern in absolute lymphocyte counts, T, B, null, and FT cells during the first 15 days after onset of rash, between measles patients who recovered and those who did not, was less clearly detectable at 21 and 42 days. Lymphocyte subpopulations, except for null cells, had reached the level of normal controls at the 3rd week after onset of rash in those who recovered. At the 3rd week of the rash lymphocyte subpopulations, except for FTcells, were still significantly below normal in children who did not recover. At the 6th week only the T-cells in addition had reached normal in these children whereas the absolute lymphocytes, B-cells, and null cells were still significantly depressed.

Measles antibodies (group A). (Fig. 4). Measles antibodies, during the 15 days after onset of rash, were below a titre of $1 / 10$ in 6 of 7 children who subsequently died and below $1 / 32$ in 6 of 9 who developed chronic chest disease. In 6 patients who recovered, there were equal numbers who had low $(<1 / 64)$ and high $(1 / 640)$ titres. One patient who died had a titre of $1 / 640$ on the 14th day after onset of rash and this rapidly fell to undetectable levels $(<1 / 2)$ on days 21 and 42 . A further patient who died had no detectable antibody on day 21 . There 


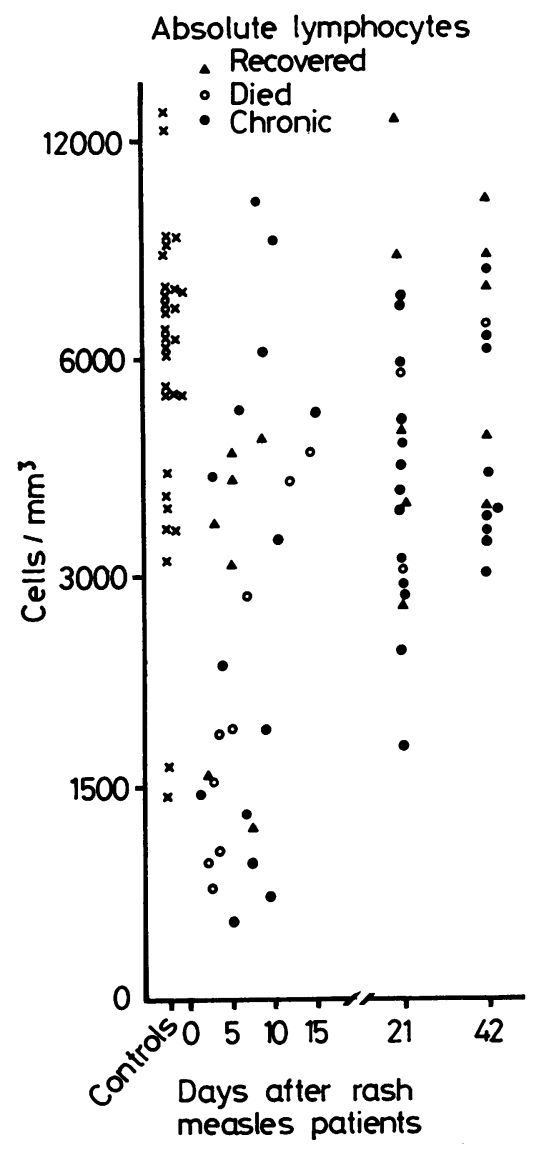

Fig. 1 Sequential absolute lymphocyte counts in group A patients and controls.

was no distinguishable pattern in antibody levels on day 21 separating those who developed chronicity from those who recovered. By day 42 most surviving patients had antibody titres of $<1 / 64$.

C3 (group A). There were no differences in C3 between children who did well and those who did not, at any stage of the disease.

\section{Discussion}

Children with measles at risk for mortality and serious morbidity have been identified by the severity of immunoparesis during the first 2 days of the rash. Estimation of lymphocyte numbers in the peripheral blood has been shown to be a reliable index of outcome in measles. More than $75 \%$ of children with

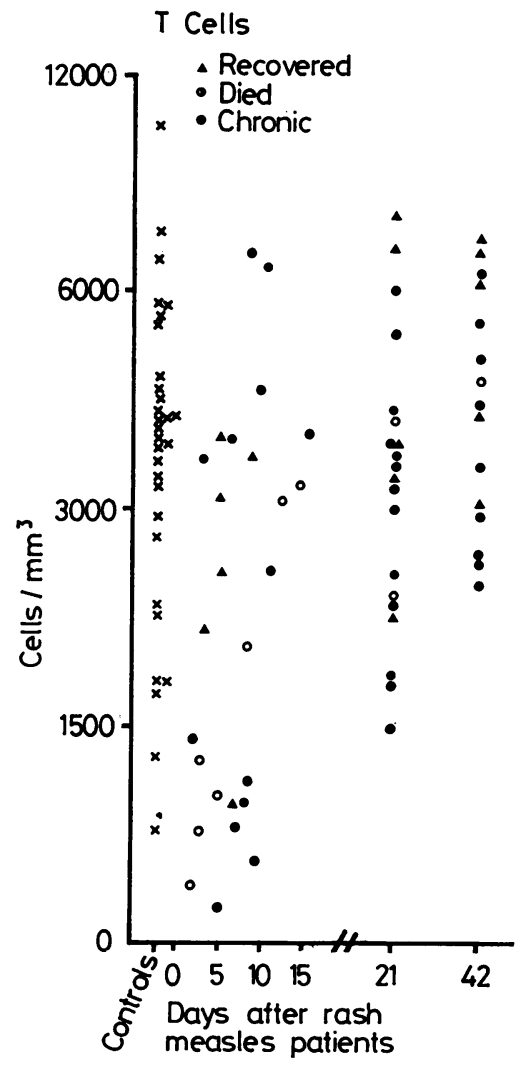

Fig. 2 Sequential T-cells in group A patients and controls.

a lymphopenia $<2000 / \mathrm{mm}^{3}$ during the early rash failed to recover; $30 \%$ died from pulmonary complications within a few days to two months of onset of the exanthem, while $47 \%$ developed chronic lung damage. When depression of immunity was less severe (lymphocyte counts $>2000 / \mathrm{mm}^{3}$ ) recovery was more frequent and mortality insignificant. However, these patients had a high incidence $(33 \%)$ of chronic lung damage. This probably reflects a more critical examination of chest $x$-rays and strict criteria for admission to hospital, with entry being restricted to the moderately and severely ill children with measles.

The profound immunosuppression during the first few days of the rash in measles which can determine prognosis has been shown to affect chiefly the T- and B-cell subpopulations with less severe effects on C3 and T-cell function assessed by phytohaemagglutinin transformation of lymphocytes (Coovadia et al., 1977). This quantitative defect in lymphocyte subpopulations was transient in most children with severe lymphopenia. However, when 


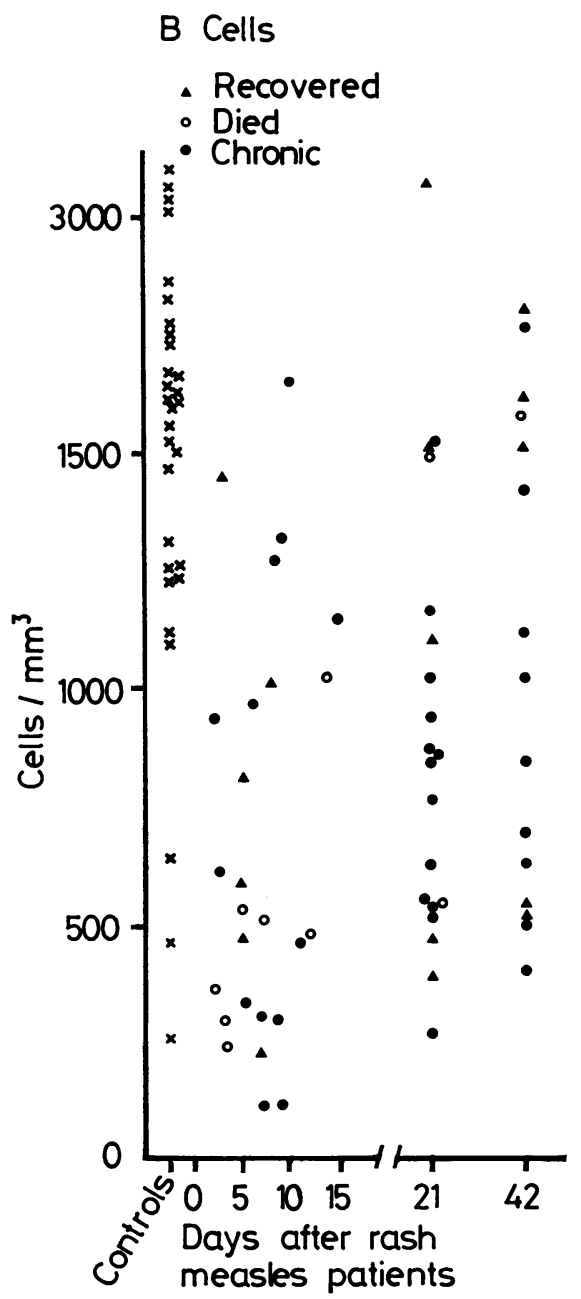

Fig. 3 Sequential B-cells in group A patients and controls.

this effect persisted for at least 15 days after appearance of the rash, it was nearly always associated with a poor outcome. $86-90 \%$ of these children with prolonged immunoparesis died or developed progressive pulmonary damage, Estimation of lymphocytes after 48 hours of the rash in those children with rapid though incomplete reversal of lymphopenia was not an accurate index of eventual recovery, continuing disease, or death. Some of these children recovered but many did not.

The predictive value of null and FT-cells is less clear. In a previous series (Coovadia et al., 1977), null cells were lower and FT higher in patients with lymphocyte counts $<2000 / \mathrm{mm}^{3}$. This study however, showed that in group A FT-cells were undetectable
Measles antibodies

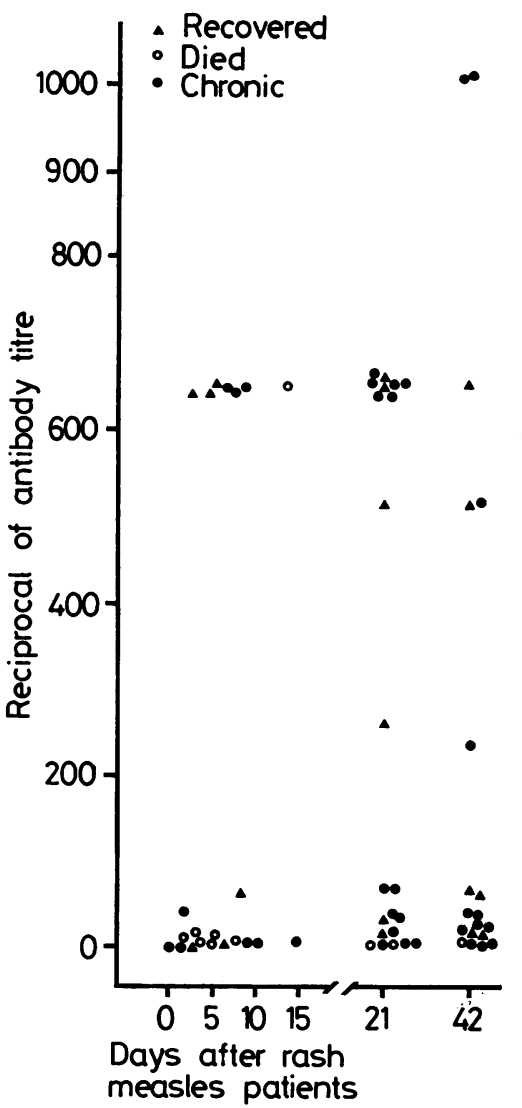

Fig. 4 Sequential measles complement-fixing antibodies in group $A$.

and null cells higher for at least 15 days after the rash in those who did not recover compared with those who did. Null cells have also been reported to be raised in patients dying from smallpox (Jackson et al., 1977). These changes cannot be meaningfully interpreted until the function of these cells is more clearly understood.

The transformation of lymphocytes by phytohaemagglutinin and the dialysed culture supernatant of measles-infected Hela cells in 12 group A patients studied sequentially was both inconsistent and unhelpful in distinguishing between those who did well and those who did not (Coovadia et al., 1977, unpublished). The other function of T-cells, particularly their co-operative helper role with B-cells which has been demonstrated to be defective in measles (McFarland, 1974), may however be critical in the development of serious complications. 
The mechanisms of lymphopenia in group A may be due to any or all of the following: an elevated cortisol level which is a frequent homeostatic response during stress; the 'trapping' of lymphocytes in peripheral lymphoid tissues; viral destruction of cells. The detection of severe lymphopenia in measles in the presence of exuberant lymphocytic formation in peripheral lymphoid tissues would make 'trapping' a likely event (Benjamin and Ward, 1932). Replication of measles virus in T- and B-lymphocytes in the peripheral blood may well lead to destruction of these cells (Joseph et al., 1975). Atrophy of the thymus, which is frequent in children dying from measles, would reduce the supply of T-cells to the periphery (White and Boyd, 1973).

The function of measles antigen-sensitive cells is probably impaired during severe measles infection. Measles antibody responses in most children in group A were poor. Complement-fixing antibodies are usually detectable within a day of the rash, attain peak levels soon after the first week, and begin to decline after 2 months (Ruckle and Rogers, 1957). All the children who subsequently died failed to produce an adequate or sustained measles antibody response. The link in this study between chronicity and antibody levels was suggestive though it was not clearly different from the response in children with a favourable outcome. The muted antibody response in those children who did badly was probably clinically important as patients with secondary immunodeficiency who die or develop fatal Hecht's giant cell pneumonia after measles also fail to produce adequate antibody (Mitus et al., 1959; Dossetor et al., 1977). Factors which are intrinsic or extrinsic to the antigen-sensitive lymphocyte may determine the quantity of specific antibody produced.

A heavy viral load which binds specific antibody and nonspecifically inhibits the measles specific immune response may have accounted for decrease in measles antibody. Diminution in antibodies in these patients may have also been due to excessive measles antigen bombarding an intrinsically abnormal lymphocyte. Either of these factors may have accounted for decreased antibody in those who did not recover and the unusually rapid diminution in antibody titres in group $\mathbf{A}$ as a whole. A genetically determined inability of the lymphocyte to respond adequately to the virus may therefore be an additional and important reason for the recognised severity of measles in some African children (Morley et al., 1963).

Acute death in measles could be due to overwhelming and irreversible immunological paralysis, detectable by lymphopenia and inadequate specific antibody response. Chronicity could be explained by less severe effects which would allow establishment of persistent virus infection. Viruses other than measles often complicate lung infection in measles (Kipps and Kaschula, 1976), and rarely brain infection in SSPE (Koprowski et al., 1970). Measles infection leading to SSPE occurs most often in children under 2 years of age (Modlin et al., 1977), when immunological responses are immature (Soothill, 1975) and infection is associated with a high mortality (Morley et al., 1963).

In this study those children who finally recovered had a more rapid reversal of lymphopenia than those who died or developed chronicity. There was incomplete immunological rehabilitation at 6 weeks in those who did not recover. However, when children with established chronic chest disease have been studied after 6 weeks, immunological recovery is almost complete (Coovadia et al., 1978). Similarly in SSPE, immunological parameters are generally normal except for alterations in measles specific immunity (Valdimarsson et al., 1974). These results suggest that long-term pulmonary and neurological sequelae of measles are probably owing to a transient widespread immunoparesis during early measles with persistent defects in specific immunity to measles and probably other viruses, whereas recovery follows less severe effects of shorter duration.

The therapeutic implication of our studies is that children with measles who are at risk for death and chronic disease can be identified early in the disease, and intervention at this stage may reverse the severe immunosuppression which leads to rapid demise or modify the immunopathological changes progressing relentlessly in some cases to permanent lung and brain damage and occasionally to death.

This study was supported by grants from the Medical Research Council, South Africa. We thank R. Cooper from Dr A. F. Hallet's Laboratory, P. Kiepiela from Dr G. Vos's Laboratory, and R. E. Formo for technical assistance. Dr F. Rooknoodeen who assisted in grading chest $x$-rays, Prof. P. M. Smythe for support, Prof. O. W. Prozesky, National Institute of Virology, for supplying measles virus, and D. Bolt and J. Pretorius for secretarial help.

\section{References}

Benjamin, B., and Ward, S. M. (1932). Leukocytic response to measles. American Journal of Diseases of Children, 44, 921-963.

Brain, P., Cox, J., Duursma, J., and Pudifin, D. J. (1976). $\mathbf{T}$ and $\mathbf{B}$ lymphocytes in three population groups. Clinical and Experimental Immunology, 23, 248-251.

Coovadia, H. M., Wesley, A., Brain, P., Henderson, L. G., Hallett, A. F., and Vos, G. H. (1977). Immunoparesis and outcome in measles, Lancet, 1, 619-621. 
Coovadia, H. M., Wesley, A., Henderson, L. G., Brain, P., Vos, G. H., and Hallett, A. F. (1978). Alterations in immune responsiveness in acute measles and chronic postmeasles chest disease. International Archives of Allergy and Applied Immunology, 56, 14-23.

Dossetor, J., Whittle, H. C., and Greenwood, B. M. (1977). Persistent measles infection in malnourished children. British Medical Journal, 1, 1633-1635.

Gowans, J. L. (1968-1969). Lymphocytes. Harvey Lectures, 64, 87-119.

Jackson, T. M., Zaman, S. N., and Huq, F. (1977). T and B rosetting lymphocytes in the blood of smallpox patients. American Journal of Tropical Medicine and Hygiene, 26, 517-519.

Joseph, B. S., Lampert, P. W., and Oldstone, M. B. A. (1975). Replication and persistence of measles virus in defined subpopulations of human leukocytes. Journal of Virology, 16, 1638-1649.

Kipps, A., and Kaschula, R. O. C. (1976). Virus pneumonia following measles. South African Medical Journal, 50, 1083-1088.

Kipps, A., Stern, L., and Vaughan, E. G. (1966). The duration and the possible significance of the depression of tuberculin sensitivity following measles. South African Medical Journal, 40, 104-108.

Koprowski, H., Barbanti-Brodano, G., and Katz, M. (1970). Interaction between papova-like virus and paramyxovirus in human brain cells: a hypothesis. Nature (London), 225, 1045-1047.

McFarland, H. F. (1974). The effect of measles virus infection on T and B lymphocytes in the mouse. I. Suppression of helper cell activity. Journal of Immunology, 113, 1978-1983.

Mitus, A., Enders, J. F., Craig, J. M., and Holloway, A. (1959). Persistence of measles virus and depression of antibody formation in patients with giant-cell pneumonia after measles. New England Journal of Medicine, 261, 882-889.

Modlin, J. F., Jabbour, J. T., Witte, J. J., and Halsey, N. A. (1977). Epidemiologic study of measles, measles vaccine, and subacute sclerosing panencephalitis. Pediatrics, 59, 505-512.

Morley, D., Woodland, M., and Martin, W. J. (1963). Measles in Nigerian children. A study of the disease in West Africa, and its manifestations in England and other countries during different epochs. Journal of Hygiene, 61, 115-134.

Papatestas, A. E., and Kark, A. E. (1974). Peripheral lymphocyte counts in breast carcinoma. An index of immune competence. Cancer (Philadelphia), 34, 2014-2017.

Ruckle, G., and Rogers, K. D. (1957). Studies with measles virus. II. Isolation of virus and immunologic studies in persons who have had the natural disease. Journal of Immunology, 78, 341-355.

Soothill, J. F. (1975). Immunity deficiency states. In Clinical Aspects of Immunology, third edition, p. 651. Edited by P. G. H. Gell, R. R. A. Coombs, and P. J. Lachmann. Blackwell: Oxford.

Starr, S., and Berkovich, S. (1964). Effect of measles, gammaglobulin modified measles, and vaccine measles on the tuberculin test. New England Journal of Medicine, 270, 386-391.

Valdimarsson, H., Agnarsdottir, G., and Lachmann, P. J. (1974). Cellular immunity in subacute sclerosing panencephalitis. Proceedings of the Royal Society of Medicine, 67, 1125-1129.

White, A. G., and Boyd, J. F. (1973). The effect of measles on the thymus and other lymphoid tissues. Clinical and Experimental Immunology, 13, 343-357.

Zacharski, L. R., and Linman, J. W. (1971). Lymphocytopenia: its causes and significance. Mayo Clinic Proceedings, 46, 168-173.

Correspondence to Dr H. M. Coovadia, Department of Paediatrics and Child Health, University of Natal Medical School, PO Box 17039, Congella 4013, Natal, South Africa. 